\title{
Comparison of bioaugmented EGSB and GAC-FBB reactors and their combination with aerobic SBR for the abatement of chlorophenols
}

\author{
D. Puyol a,*, V.M. Monsalvo ${ }^{\text {a }}$, S. Sanchis ${ }^{\text {a }}$, J.L. Sanz ${ }^{\text {b }}$, A.F. Mohedano ${ }^{\text {a }}$, J.J. Rodriguez ${ }^{\text {a }}$ \\ a Sección de Ingeniería Química, Facultad de Ciencias, Universidad Autónoma de Madrid, C/Francisco Tomas y Valiente 7, 28924 Madrid, Spain \\ ${ }^{\mathrm{b}}$ Departamento de Biologia Molecular, Facultad de Ciencias, Universidad Autonoma de Madrid, C/Darwin 7, 28049 Madrid, Spain
}

\section{H I G H L I G H T S}

- Coupling bioaugmented GAC-FBBR and aerobic SBR was effective for 246TCP abatement.

- 246TCP was anaerobically dechlorinated to 4CP.

- Bioaugmentation with Desulfitobacterium spp. improves the stability.

- GAC-FBBR enhances the stability and dechlorination efficiency.

- 4CP and ecotoxicity were efficiently abated in the aerobic stage.

\section{A R T I C L E I N F O}

\section{Article history:}

Received 8 April 2014

Received in revised form 30 July 2014

Accepted 31 July 2014

Available online 9 August 2014

\section{Keywords:}

Biofilms

Chlorophenols

Combined systems

Granular reactors

Sequencing batch reactor
G R A P H I C A L A B S T R A C T

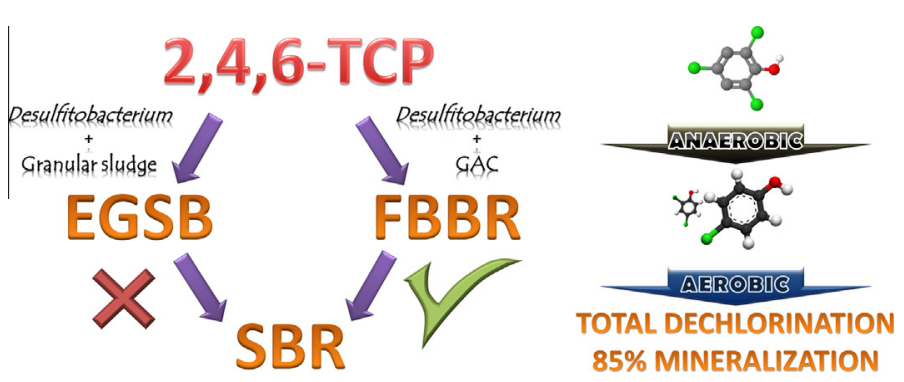

\begin{abstract}
A B S T R A C T
The biological abatement of 2,4,6-trichlorophenol (246TCP) and its chlorinated degradation byproducts using anaerobic and aerobic biological reactors coupled in series has been studied. The performance of an anaerobic fluidized bed biofilm reactor (FBBR) and expanded granular sludge bed (EGSB) reactors bioaugmented with Desulfitobacterium strains was compared within a wide range of 246TCP loading rates. The bioaugmentation of an EGSB reactor with Desulfitobacterium strains enhanced the chlorophenols removal efficiency and the stability against high toxic shocks. The FBBR showed an even higher stability, but also improved the dechlorination efficiency and required a shorter start-up period than the bioaugmented EGSB reactor. Thus, it was selected as the preferred anaerobic system. The subsequent treatment of the effluents from the anaerobic reactors in an aerobic sequencing batch reactor allowed complete dechlorination and improved mineralization up to $85 \%$ TOC reduction with a substantial abatement of the ecotoxicity, which was diminished in more than $80 \%$.
\end{abstract}

(c) 2014 Elsevier B.V. All rights reserved.

\section{Introduction}

The development of effective solutions for the treatment of a wide diversity of industrial wastewaters containing highly toxic

\footnotetext{
* Corresponding author. Tel.: +34 677894680.

E-mail addresses: daniel.puyol@uam.es (D. Puyol), victor.monsalvo@uam.es (V.M. Monsalvo), sonia.sanchis@uam.es (S. Sanchis), joseluis.sanz@uam.es (J.L. Sanz), angelf.mohedano@uam.es (A.F. Mohedano), juanjo.rodriguez@uam.es (J.J. Rodriguez)
}

chlorinated organic pollutants has gained a growing interest in the last decade. 2,4,6-Trichlorophenol (246TCP) is a well-known wood, leather and textile preservative and it has been widely used as a precursor in the synthesis of the biocides 2,3,4,6-tetrachlorophenol and pentachlorophenol until their prohibition by the Rotterdam Convention. It can be present in wastewater of the pulp industry resulting from the widely used ECF-type pulp bleaching process [1]. It has been also detected in groundwater [2] and in contaminated barrel-aged wine from Quercus sp. oak wood [3]. It 
has been described as genotoxicant [2] and the US-EPA has claimed about the high toxicity of $246 \mathrm{TCP}$ in contact with the human skin. Therefore, it has been included in the List of Priority Pollutants of the US-EPA and it is also listed in the European Directive 2006/ 11 /EC on pollution caused by certain dangerous substances discharged into the aquatic environment of the Community (List I, organohalogen compounds). Besides its own high toxicity it is recognized as a precursor in the formation of some polychlorinated dibenzo-p-dioxins (PCDDs) and dibenzofurans (PCDFs) [4].

High rate anaerobic systems such as upflow anaerobic sludge blanket (UASB) reactor, expanded granular sludge bed (EGSB) reactor and fluidized bed biofilm reactor (FBBR) have been increasingly used for treating a wide range of industrial off-streams particularly toxicant-bearing wastewaters [5]. These systems can deal efficiently with high organic loads. Among the anaerobic high-rate technologies, the EGSB and FBBR systems have been claimed as highly efficient and cost-effective solutions. The former can be operated within a wide range of upflow rate (2-10 $\left.\mathrm{m} \mathrm{h}^{-1}\right)$, allowing the treatment of a diversity of wastewaters including those containing toxic pollutants. The second uses a fluidized media with high adsorption capacity, such as activated carbon, providing biomass support and toxicants uptake [6]. A comparison between these two technologies for the treatment of chlorophenols is still needed.

EGSB reactors and FBBRs have been used for treating chlorophenolic wastewaters [7]. The degradation of the resulting monoaromatics from dechlorination can be also achieved by these technologies [8]. Despite anaerobic cultures are capable of dechlorinating polychlorinated compounds [9], they show limitations for degrading monochlorophenols (MCPs) which then can remain in the final discharges [10]. In fact, these compounds have been described as the hardest aromatic compounds to be anaerobically biodegraded among 46 different aromatics [11]. Different intensification strategies have been evaluated as potential solutions. Bioaugmentation has been successfully applied for improving the anaerobic biodegradability of chlorophenols, reducing the acclimation time [12]. However, better knowledge on the dechlorination of polychlorinated compounds and the resulting MCPs upon anaerobic treatment is needed.

Despite the recalcitrant nature of MCPs, some efforts have been addressed towards the use of aerobic biological processes [13]. Among the different biological systems used for the breakdown of MCPs, sequencing batch reactors (SBR) have important advantages such as reduced space, easy control, nutrients removal and low energy requirements. The versatility of SBR allows modifying the operation and control strategies so that can be adapted to process a wide range of organic loads [14-16]. This technology has been evaluated for the treatment of different chlorophenols, analyzing the influence of the sequence, temperature and acclimation strategy, as well as the breakdown pathways of these compounds [14]. However, this system has shown a fairly low efficiency when dealing with polychlorinated species [7]. The combination of anaerobic and aerobic biological systems could be an interesting option for that kind of pollutants. The effective coupling of anaerobic and aerobic bioreactors has been claimed in the last years as a potential solution for different wastewaters [17].

The aim of this work is to compare the behavior of EGSB reactors and granular activated carbon (GAC)-FBBR bioaugmented with Desulfitobacterium spp. strains and to evaluate their combination with a subsequent aerobic SBR for the abatement of chlorophenols. The two-step anaerobic-aerobic biological treatment has been analyzed as a potential solution for the breakdown of 246TCP at relatively high loading rate (up to around $1300 \mu \mathrm{mol} \mathrm{L}^{-1} \mathrm{~d}^{-1}$ ). The performance of the anaerobic reactors was evaluated in terms of chlorophenols conversion and overall dechlorination as well as stability towards toxic shocks of
246TCP. In addition, an innovative approach has been used for a better operation of an aerobic SBR as post-treatment system.

\section{Materials and methods}

\subsection{Biodegradability and inhibition anaerobic tests}

The specific methanogenic activity (SMA) tests were performed according to a previous work [10].

Anaerobic biodegradability of 246TCP, 2,4-dichlorophenol (24DCP) and 4-chlorophenol (4CP) was evaluated using $250 \mathrm{~mL}$ serum bottles inoculated with active granular sludge at $1.5 \mathrm{~g} \mathrm{~L}^{-1}$ of volatile suspended solids (VSS). The temperature and $\mathrm{pH}$ were set at $30 \pm 1^{\circ} \mathrm{C}$ and $7 \pm 0.1$, respectively. The macro and micronutrients media were prepared according to Puyol et al. [10]. Bicarbonate was added at $4 \mathrm{~g} \mathrm{~L}^{-1}$ to provide alkalinity and the medium was supplemented with $100 \mathrm{mg} \mathrm{L}^{-1} \mathrm{Na}_{2} \mathrm{~S} \cdot 10 \mathrm{H}_{2} \mathrm{O}$ and flushed for five minutes with $\mathrm{N}_{2}: \mathrm{CO}_{2}(80: 20 \mathrm{v} / \mathrm{v})$ in order to assure anaerobic conditions. 246TCP, 24DCP and 4CP were tested at concentrations up to $100 \mathrm{mg} \mathrm{L}^{-1}$ during $10 \mathrm{~d}$. No extra carbon source was added. Anaerobic granular sludge from a full-scale UASB reactor treating brewery wastewater (Mahou, Guadalajara, Spain) was used as inoculum.

The amount of chlorophenols biosorbed onto the biomass was quantified following a partial detachment, extractive and digestive method. The sludge was centrifuged and washed and the chlorophenols were extracted with acetonitrile/water for determining the adsorbed fraction of chlorophenols. The chlorophenols absorbed inside the sludge were subsequently extracted by digestion of the cells with lysozyme [18].

Methanogenesis inhibition tests were performed in the same conditions as the biodegradability tests, but adding a standard carbon source for methanogenesis, consisting of a mixture of acetate:propionate:butyrate at $1: 1: 1$ (by weight) equivalent to a COD of $4 \mathrm{~g} \mathrm{~L}^{-1}$. Chlorophenols (246TCP, 24DCP and 4CP) were tested at concentrations up to $250 \mathrm{mg} \mathrm{L}^{-1}$ for $15 \mathrm{~d}$. The previous acclimation of the sludge was studied as a determining factor. Experiments with non-acclimated microorganisms were conducted with the aforementioned brewery granular sludge. The biomass source for the acclimated sludge experiments had two different origins. Granular sludge adapted to 4CP and 24DCP was retrieved from a lab-scale EGSB reactor treating 24DCP for $180 \mathrm{~d}$ [10], whereas the sludge adapted to 246TCP was withdrawn from the non-bioaugmented EGSB reactor described above at the end of the experiments. Methane was measured by a bioprocess control automatic methane potential test system (AMPTS, Bioprocess Control, Sweden). The 50\% effective concentration $\left(\mathrm{EC}_{50}\right)$ values were estimated by the following equation:

$\mathrm{SMA}=\mathrm{SMA}_{\max } /\left[1+\left(I / E C_{50}\right)^{n}\right]$

where $\mathrm{SMA}_{\max }$ represents the maximum SMA (g CH4-COD g-1 VSS $d-1), I$ is the chlorophenol concentration $(\mu \mathrm{M})$ and $n$ is the inhibition order (dimensionless). Experimentally measured SMA values were fitted to Eq. (1) by means of non-least square minimization of error using the Levenberg-Mardquardt algorithm (Origin 8.0, OriginLab, Northampton, MA, USA).

\subsection{Anaerobic continuous experiments}

\subsubsection{Reactors configuration}

Long-term anaerobic experiments were performed at $30 \pm 1{ }^{\circ} \mathrm{C}$ in three $5.4 \mathrm{~L}$ polymethylmethacrylate reactors of $10 \mathrm{~cm}$ internal diameter and $72.5 \mathrm{~cm}$ height. The three-phase separator was located $15 \mathrm{~cm}$ below the top of each reactor. Two of them were operated as EGSB reactors inoculated with $100 \mathrm{~g}$ VSS of an 
anaerobic granular sludge retrieved from a lab-scale EGSB reactor enriched with 24DCP [10]. $\mathrm{CO}_{2}$ was removed from biogas using a Mariotte flask with a $4 \mathrm{M} \mathrm{NaOH}$ solution trap, and methane was measured with a wet gas-meter (Schlumberger, Houston, TX, USA). The other reactor, operated as FBBR, was loaded with $1 \mathrm{~kg}$ of raw granular activated carbon (GAC) from Merck (Whitehouse Station, NJ, USA) characterized by a BET surface area $\left(S_{\mathrm{BET}}\right)$ of $917 \mathrm{~m}^{2} \mathrm{~g}^{-1}$, an external or non microporous area of $120 \mathrm{~m}^{2} \mathrm{~g}^{-1}$ and micro and mesopore volumes of 0.33 and $0.04 \mathrm{~cm}^{3} \mathrm{~g}^{-1}$, respectively. Methane was not monitored in the FBBR. External recirculation in the EGSB and FBBR reactors was provided by means of peristaltic pumps for fluidizing both the granular sludge and GAC-biofilm at upflow rates of 4 and $10 \mathrm{~m} \mathrm{~h}^{-1}$, respectively.

\subsubsection{Synthetic wastewater}

The synthetic feed was prepared as was described before for the anaerobic batch experiments. Sucrose, ethanol and yeast extract (3:2:0.1, expressed as COD) were used as carbon sources. The synthetic medium was dosed from a stock solution of $25 \mathrm{mM}$ 246TCP (Sigma-Aldrich, St. Louis, MO, USA) in $0.1 \mathrm{M} \mathrm{NaOH}$.

\subsubsection{Bioaugmentation and start-up}

One of the EGSB reactors (EGSB-B) and the FBBR were bioaugmented with three strains belonging to Desulfitobacterium genus (Desulfitobacterium hafniense PCP-1, D. hafniense TCP-A, and Desulfitobacterium chlororespirans). These species have been previously reported as very versatile bacteria capable of dechlorinating a wide range of chlorinated organics. Their specific growth rate is relatively elevated so that it is quite easy to grow them in batch and use for bioaugmentation. All of them are able of dechlorinating in ortho-position, but $D$. hafniense PCP- 1 is even capable of achieving para-dechlorination [19]. These species were previously grown in a specific medium for Desulfitobacterium spp. until reaching the maximum biomass concentration (see Supplementary Material). Then, $350 \mathrm{~mL}$ of each culture were added to the EGSB-B and the FBBR reactors. Bioaugmentation was performed in batch mode during $12 \mathrm{~d}$. Carbon source and 246TCP were added daily at $7.5 \mathrm{~g} \mathrm{COD} \mathrm{L}^{-1}$ and $50 \mu \mathrm{M}$, respectively. The control EGSB reactor was not bioaugmented (EGSB-NB). The three reactors were started at an organic loading rate (OLR) of $7.5 \mathrm{~g} \mathrm{COD} \mathrm{L}^{-1} \mathrm{~d}^{-1}$, which was reduced to the half after $90 \mathrm{~d}$ of continuous operation for promoting MCPs biodegradation [10]. The 246TCP loading rate (246TCP-LR) was increased stepwise after the bioaugmentation from 50 to $1300 \mu \mathrm{mol} \mathrm{L}^{-1} \mathrm{~d}^{-1}$, in different operational stages.

\subsubsection{Stability analyses}

Two sharp increases of 246TCP-LR were applied to EGSB and FBBR reactors, a step one where the $246 T C P-L R$ was raised to $5000 \mu \mathrm{mol} \mathrm{L}^{-1} \mathrm{~d}^{-1}$ and maintained for $22 \mathrm{~h}$, and a pulse injection, allowing a 246TCP concentration of around $5000 \mu \mathrm{M}$ inside the reactor. A stabilization time was let between both actions where the $246 \mathrm{TCP}-\mathrm{LR}$ was set at $1300 \mu \mathrm{mol} \mathrm{L}^{-1} \mathrm{~d}^{-1}$. COD, chlorophenols concentration and methane production (in the EGSB reactors) were monitored.

\subsubsection{Adsorption}

The following mass balance serves to describe the sorption of 246TCP into the GAC of the FBBR:

$Q \cdot C_{\mathrm{o}}-Q \cdot C=\left(V_{\mathrm{T}}-V_{\mathrm{C}}\right) \frac{\partial C}{\partial t}+M_{C} \frac{\partial q}{\partial t}$

where $Q$ is the inlet flow rate $\left(\mathrm{Ld}^{-1}\right), V_{\mathrm{T}}$ and $V_{\mathrm{c}}$ are volumes of the reactor and GAC, respectively (L), $C_{o}$ and $C$ are the influent and effluent 246TCP concentrations $(\mu \mathrm{M}), M_{\mathrm{c}}$ is the mass of GAC $(\mathrm{g})$ and $q$ is the amount of 246TCP adsorbed onto the GAC ( $\mu$ mol 246TCP g $\left.{ }^{-1} \mathrm{GAC}\right)$.
Using the Freundlich equation to describe the adsorption equilibrium in Eq. (2) leads to:

$$
\left(V_{\mathrm{T}}-V_{\mathrm{C}}\right) \frac{\partial C}{\partial t}+M_{\mathrm{C}} \cdot K_{\mathrm{f}} \cdot \frac{1}{n} \cdot C^{\left(\frac{1}{n}-1\right)} \cdot \frac{\partial C}{\partial t}+Q \cdot C-Q \cdot C_{\mathrm{o}}=0
$$

Each stage corresponding to the different 246TCP-LR tested was separately simulated by using Scientist 3.0 software (Micromath, USA). Integration was performed by the EPISODE numerical method for Stiff systems. The boundary conditions for each stage result from the values obtained in the previous one.

\subsection{Aerobic degradation tests}

The biodegradability of the effluents from 246TCP treatment in EGSB-B and FBBR reactors was assessed by respirometry in a liquid-static-static (LSS) respirometer following the fast biodegradability test developed by Polo et al. [20]. The sample $(1 \mathrm{~L})$ was mixed with the biomass ( $350 \mathrm{mg} \mathrm{VSS} \mathrm{L}^{-1}$ ) and aerated for $24 \mathrm{~h}$. The specific oxygen uptake rate (SOUR), COD and concentration of the main byproducts in the EGSB-B and FBBR effluents (246TCP, 24DCP, 4CP, acetate and propionate) were measured in each experiment. The stoppered reaction flasks were placed in a thermostatic bath and continuously stirred by magnetic bars.

The contribution of abiotic processes such as volatilization and adsorption onto the sludge flocs was evaluated. Adsorption of chlorophenols was measured after extracting the samples in Soxhelt following the US-EPA 8041 method. Volatilization tests were performed under identical operating conditions to those of the biodegradation experiments but in absence of biomass.

\subsection{Aerobic long-term SBR experiments}

Sequencing batch reactors of $2.1 \mathrm{~L}$ with a thermostatised water jacket to control the operating temperature were used. They were equipped with dissolved oxygen and $\mathrm{pH}$ probes. Peristaltic pumps were used for feed and discharge as well as for the addition of $\mathrm{NaOH}$ solution $(3 \mathrm{M})$ used for $\mathrm{pH}$ control. Air was continuously

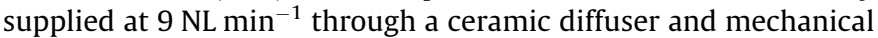
stirring was maintained. The experiments were conducted in a series of fixed-time stages in sequences of $12 \mathrm{~h}$ as follows: anoxic filling $(1 \mathrm{~h})$, aerated reaction $(9.5 \mathrm{~h})$, settling $(1 \mathrm{~h})$ and draw $(0.5 \mathrm{~h})$. The experiments were carried out at $25 \pm 1{ }^{\circ} \mathrm{C}$. HRT was studied between 16 and $80 \mathrm{~h}$, and sludge retention time was fixed at $30 \mathrm{~d}$. Biomass concentration in the reactors was maintained at around $2500 \mathrm{mg} \mathrm{VSS} \mathrm{L}^{-1}$. The inoculum was collected from a lab-scale SBR enriched with 4CP during 2 months at $390 \mu \mathrm{mol}$ $4 \mathrm{CP} \mathrm{L}^{-1} \mathrm{~d}^{-1}$.

\subsection{Analytical methods}

COD, total and volatile suspended solids (TSS and VSS), $\mathrm{V}_{30}$, and sludge volumetric index (SVI) were determined following the APHA standard methods [21].

4-Chlorocatechol and 4CP were quantified by HPLC/UV (Prostar, Varian, USA) using a $\mathrm{C}_{18}$ column as stationary phase (Microsorb MW-100-5) and a mixture of acetonitrile and milli-Q $\mathrm{H}_{2} \mathrm{O}(40: 60$, by vol.) as mobile phase, whereas 246TCP and 24DCP were analyzed using a mobile phase consisting of acetonitrile and $0.025 \mathrm{M}$ acetic acid (60:40, vol.). The flow rate was maintained at

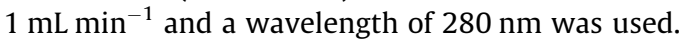

Total organic carbon (TOC) was measured using an OI Analytic Model 1010 TOC apparatus. Ecotoxicity determinations were carried out by the Microtox Acute Toxicity Test (SCI 500 Analyser) using a freeze-dried preparation of the marine bacterium Vibrio fischeri as described in ISO 11348-3. The results were expressed 
in toxicity units (TU), calculated from the 50\% inhibitory concentration $\left(\mathrm{IC}_{50}\right)$ values $\left(\mathrm{TU}=100 / \mathrm{IC}_{50}\right)$.

\subsection{Scanning electron microscopy (SEM)}

The morphology of the granular sludge from the EGSB reactors and the biofilm supported on the GAC in the FBBR was analyzed by SEM with a Philips XL30 microscope. Samples were cut and fixed according to the method developed by Alphenaar et al. [22].

\subsection{Fluorescence in situ hybridization (FISH)}

Representative samples (around $0.03 \mathrm{~g}$ ) of the anaerobic granular sludge and GAC-biofilm from the EGSB reactors and FBBR, respectively, were re-suspended in $890 \mu \mathrm{L}$ of a phosphate buffer solution (PBS, $130 \mathrm{mM} \mathrm{NaCl}, 10 \mathrm{mM} \mathrm{Na}_{2} \mathrm{PO}_{4} / \mathrm{NaH}_{2} \mathrm{PO}_{4}, \mathrm{pH}=7.2-7.4$ ) and dispersed by sonication (average power $0.50 \mathrm{~W}$, frequency 0.9 cycles s $^{-1}$ ). The FBBR samples were subsequently centrifuged at $500 \mathrm{rpm}$ for $2 \mathrm{~min}$ to separate the GAC from the biofilm and recover the supernatant. Mixtures from EGSB and FBBR were fixed with formaldehyde ( $4 \% \mathrm{v} / \mathrm{v}$ final concentration) for $6 \mathrm{~h}$, centrifuged $5 \mathrm{~min}$ at $13,000 \mathrm{rpm}$, the pellets washed with $1 \mathrm{~mL}$ PBS three times, and finally re-suspended in ethanol:PBS 50:50 v/v and conserved at $-20{ }^{\circ} \mathrm{C}$ before analyses. Specific probes for Bacteria (EUB-338), Archaea (ARC-915) [23], Desulfitobacterium spp. (Dsf326) and D. hafniense (Dsf576) [24] amended with Cy3 were selected. FISH was performed according to protocols described previously by Amann et al. [23]. After hybridization, the specimens were stained with 4',6'-diamidino-2-phenylindole (DAPI) (1 $\left.\mathrm{mg} \mathrm{mL}^{-1}\right)$. Escherichia coli, Methanosaeta concilii and D. hafniense PCP-1 were used as positive controls for EUB-338, ARC-915 and both Dsf326 and Dsf576, respectively. D. hafniense PCP-1 hybridization with NON338 [25] was used as negative control. Hybridized samples were observed using an epifluorescense microscope equipped with Cy3 and DAPI filters (Axioskop, Berkochen, Germany) and a digital camera. Counting was performed by taking pictures from 20 random fields for each sample, corresponding theoretically to around 1000 stained cells.

\subsection{Data analysis}

The results reported were the average values from duplicate runs. Control experiments were conducted for all the batch tests. The standard errors of the measurements were always lower than $5 \%$.

\section{Results and discussion}

\subsection{Biodegradability and inhibition anaerobic tests}

Fig. 1 shows the time course of 246TCP, 24DCP and 4CP in the anaerobic batch experiments with non-acclimated granular sludge at different starting concentrations. 246TCP was almost completely converted in $10 \mathrm{~d}$ at starting concentrations below $300 \mu \mathrm{M}$. In the case of 24DCP an initial stage of high disappearance rate was observed due to biosorption, followed by biodegradation at almost constant rate even at the highest initial concentration tested. The main chlorinated by-product upon 246TCP and 24DCP biodegradation was $4 \mathrm{CP}$, suggesting that the ortho-dechlorination is the predominant degradation pathway. This last species appears almost refractory to anaerobic biodegradation except at the lowest concentration tested $(40 \mu \mathrm{M})$.

The inhibitory effect of 246TCP, 24DCP and 4CP on the methanogenic activity of acclimated and non-acclimated granular sludge has been analyzed by calculating the $\mathrm{EC}_{50}$ values. The decrease of

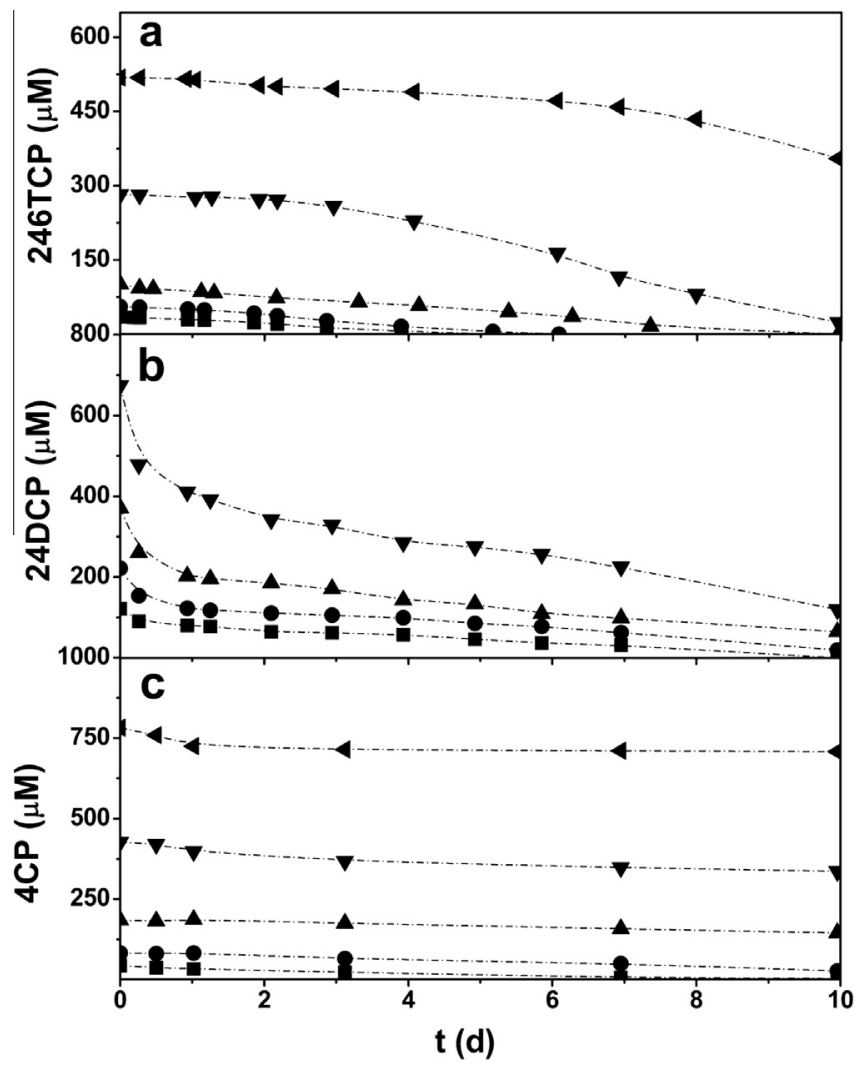

Fig. 1. Time-evolution of $246 \mathrm{TCP}$ (a), 24DCP (b) and 4CP (c) in the anaerobic batch experiments at different initial concentrations.

the number of chloride in the phenolic ring and the acclimation of the biomass reduce considerably the toxicity of chlorophenols towards methanogens. The $\mathrm{EC}_{50}$ values for non-acclimated biomass were 122, 276 and $311 \mu \mathrm{mol} \mathrm{L}^{-1}$ for 246TCP, 24DCP and $4 C P$, respectively. The acclimation of the biomass increased these values up to 208,798 and $948 \mu \mathrm{mol} \mathrm{L}^{-1}$, respectively, indicating that methanogens can deal with much higher chlorophenols concentrations once the biomass is properly acclimated. It is therefore crucial to optimize the acclimation step for achieving high dechlorination efficiency and therefore ensuring a stable performance of a methanogenic anaerobic reactor.

\subsection{Anaerobic reactors performance}

The anaerobic reactors were operated for $248 \mathrm{~d}$ at different 246TCP loads, which were gradually increased along the successive operational stages for the aiming of acclimation. Table 1 summarizes the results obtained for the EGSB-NB and EGSB-B reactors. The high and stable values of COD removal efficiency and methane yield indicate the good performance of the EGSB system. Beyond the 8th stage, where the 246TCP loading rate acquired fairly high values, a decrease of the COD removal efficiency was observed although without significant effect on the methane yield. The analysis of the Archaea population in the granular sludge by FISH showed an increasing percentage of those microorganisms upon the testing time as can be seen in Fig. 2a and b. Previous works have reported a certain sensitivity of acetogenic bacteria and obligated hydrogen-producing acetogens, like propionate and lactate oxidizers, to the presence of chlorophenols [18,26]. It is therefore suggested that the decrease of the COD removal efficiency could be derived from partial inhibition of biological steps previous to methanogenesis. 


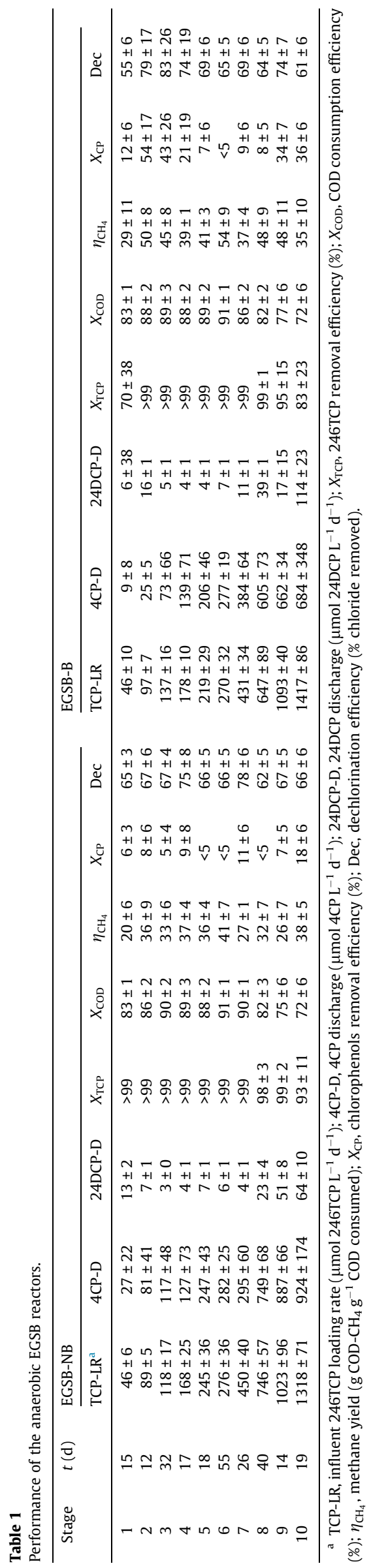

The fate of 246TCP and its degradation by-products is also summarized in Table 1. Fairly low percentages of chlorophenols removal (calculated as the difference between the inlet 246TCP molar concentration and the sum of the outlet molar concentrations of all the chlorophenols with respect to the inlet 246TCP molar concentration) were achieved (5-10\%) in the non-bioaugmented EGSB reactor. However the overall dechlorination efficiency was maintained in general above $65 \%$ reaching more than $75 \%$ in some stages since the major chlorophenol in the exiting stream was by far $4 \mathrm{CP}$ ( $>80 \%$ on molar basis). The chlorophenols removal efficiency decayed somewhat as the 246TCP loading rate increased beyond $180-200 \mu \mathrm{mol} \mathrm{L}^{-1} \mathrm{~d}^{-1}$ and seemed to recover moderately towards the end of the experiment suggesting some acclimation of the biomass.

The bioaugmentation of EGSB clearly improved the chlorophenols removal efficiency and allowed also a moderate increase of the methane yield although no significant effect was observed on COD reduction and overall dechlorination efficiency. The degradation pathway proceeded also through o-dechlorination of 246TCP to $4 \mathrm{CP}$, but $4 \mathrm{CP}$ concentration in the effluent was lower than in the non-bioaugmented EGSB reactor, probably due to partial $p$ dechlorination of $4 \mathrm{CP}$. To elucidate the differences found between the two reactors, the development of Desulfitobacterium genus was analyzed by FISH. The time course of $D$. hafniense, D. chlororespirans and the total Desulfitobacterium genus in EGSB reactors is shown in Fig. 2a and $\mathrm{b}$. The presence of $D$. hafniense in the EGSB-NB was detected in the inoculum, since the biomass was previously adapted to $24 \mathrm{DCP}$. The relative population of $D$. hafniense within the Desulfitobacterium genus in both reactors remained almost constant at around $30-35 \%$ of the total biomass, indicating a wellestablished population of this species in the granules. D. chlororespirans was only found in the EGSB-B after being externally added in this system by bioaugmentation. However, the relative abundance of this species seemed to decrease during the first $60 \mathrm{~d}$ of operation, when an important loss of the external layer of the granules was observed by SEM, probably caused by the toxic shock associated to the presence of chlorophenols (see Supplementary Material, Fig. S2). As the biomass was acclimating to the increasing 246TCP load, this layer seemed to be restored and D. chlororespirans appeared to establish within the microbial ecosystem, increasing its population in the granular sludge, thus leading to improved dechlorination.

Table 2 summarizes the operating conditions and performance of the FBBR. Both the chlorophenols removal and overall dechlorination efficiencies were much higher than the observed in the EGSB reactors. Almost complete disappearance of chlorinated species occurred during the first stages, probably due in great part to sorption onto the GAC-biofilm. In order to analyse more in depth the fate of 246TCP, its adsorption onto the supporting GAC was studied, assuming that the adsorption equilibrium follows the Freundlich equation as postulated by other authors for similar adsorbents [27]. Previous experiments showed that equilibrium was reached in less than $24 \mathrm{~h}$ (see Supplementary Material). The adsorption equilibrium tests were performed in stirred stoppered polyethylene bottles using GAC colonized with biofilms and the data were fitted to the Freundlich equation $\left(q=\mathrm{K}_{\mathrm{f}} \cdot \mathrm{C}^{1 / n}\right.$, where $q$ is the amount adsorbed, here in $\mu \mathrm{mol} \mathrm{g}^{-1}$, and $C$ is the equilibrium concentration, $\mu \mathrm{M})$. Values of 39.9 and $3.1\left(R^{2}=0.97\right)$ were obtained for $K_{\mathrm{f}}$ and $n$, respectively. A more detailed explanation of the experimental procedure for adsorption experiments can be accessed in Supplementary Material. Simulation of the adsorption process on the GAC added into the FBBR was carried out by Eq. (3). The predicted values of the exit concentration of 246TCP by considering only adsorption onto GAC are depicted in Fig. 3 (line). According to the predicted curve saturation of GAC is accomplished in about 60 days (first three stages). However, the experimental 


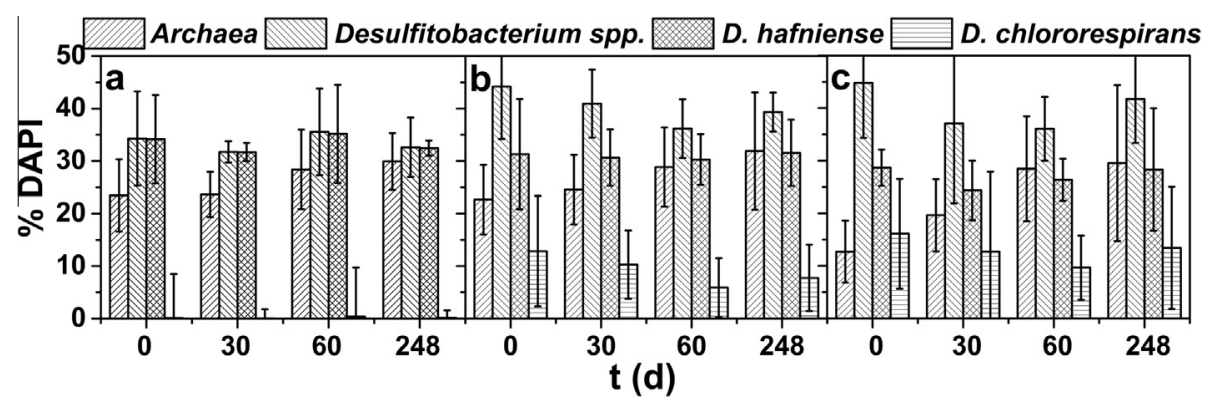

Fig. 2. Time course of Archaea and Desulfitobacterium spp. in EGSB-NB (a), EGSB-B (b) and FBBR (c) reactors.

Table 2

Performance of the anaerobic FBBR.

\begin{tabular}{|c|c|c|c|c|c|c|c|c|}
\hline \multirow[t]{2}{*}{ Stage } & \multirow[t]{2}{*}{$t(\mathrm{~d})$} & \multicolumn{7}{|l|}{ FBBR } \\
\hline & & TCP-LR ${ }^{\mathrm{a}}$ & 4CP-D & 24DCP-D & $X_{\mathrm{TCP}}$ & $X_{\mathrm{COD}}$ & $X_{\mathrm{CP}}$ & Dec \\
\hline 1 & 15 & $41 \pm 5$ & $<1$ & $<1$ & $>99$ & $19 \pm 4$ & $>99$ & $>99$ \\
\hline 2 & 12 & $87 \pm 19$ & $<1$ & $<1$ & $>99$ & $35 \pm 7$ & $>99$ & $>99$ \\
\hline 3 & 32 & $106 \pm 15$ & $<1$ & $<1$ & $>99$ & $35 \pm 3$ & $>99$ & $>99$ \\
\hline 4 & 17 & $143 \pm 17$ & $<1$ & $<1$ & $>99$ & $38 \pm 10$ & $>99$ & $>99$ \\
\hline 5 & 18 & $185 \pm 23$ & $7 \pm 5$ & $<1$ & $>99$ & $67 \pm 9$ & $97 \pm 9$ & $99 \pm 9$ \\
\hline 6 & 55 & $255 \pm 27$ & $33 \pm 24$ & $12 \pm 7$ & $>99$ & $68 \pm 5$ & $83 \pm 10$ & $93 \pm 10$ \\
\hline 7 & 26 & $375 \pm 37$ & $82 \pm 28$ & $6 \pm 7$ & $99 \pm 1$ & $82 \pm 6$ & $74 \pm 4$ & $90 \pm 4$ \\
\hline 8 & 40 & $633 \pm 122$ & $264 \pm 71$ & $31 \pm 35$ & $98 \pm 4$ & $79 \pm 5$ & $51 \pm 8$ & $81 \pm 8$ \\
\hline 9 & 14 & $933 \pm 96$ & $306 \pm 65$ & $45 \pm 19$ & $98 \pm 2$ & $79 \pm 4$ & $59 \pm 8$ & $84 \pm 8$ \\
\hline 10 & 19 & $1078 \pm 78$ & $344 \pm 122$ & $57 \pm 23$ & $99 \pm 1$ & $80 \pm 4$ & $63 \pm 9$ & $85 \pm 9$ \\
\hline
\end{tabular}

a TCP-LR, influent 246TCP loading rate ( $\mu$ mol 246TCP L $\left.{ }^{-1} \mathrm{~d}^{-1}\right) ; 4 C P-D, 4 C P$ discharge $\left(\mu \mathrm{mol} 4 \mathrm{CP} \mathrm{L}^{-1} \mathrm{~d}^{-1}\right) ; 24 \mathrm{DCP}-\mathrm{D}, 24 \mathrm{DCP}$ discharge $\left(\mu \mathrm{mol} 24 \mathrm{DCP} \mathrm{L}^{-1} \mathrm{~d}^{-1}\right.$ ); $X_{\mathrm{TCP}}, 246 \mathrm{TCP}$ removal efficiency (\%); $X_{\mathrm{COD}}$, COD consumption efficiency (\%); $X_{\mathrm{CP}}$, chlorophenols removal efficiency (\%); Dec: dechlorination efficiency (\% chloride removed).

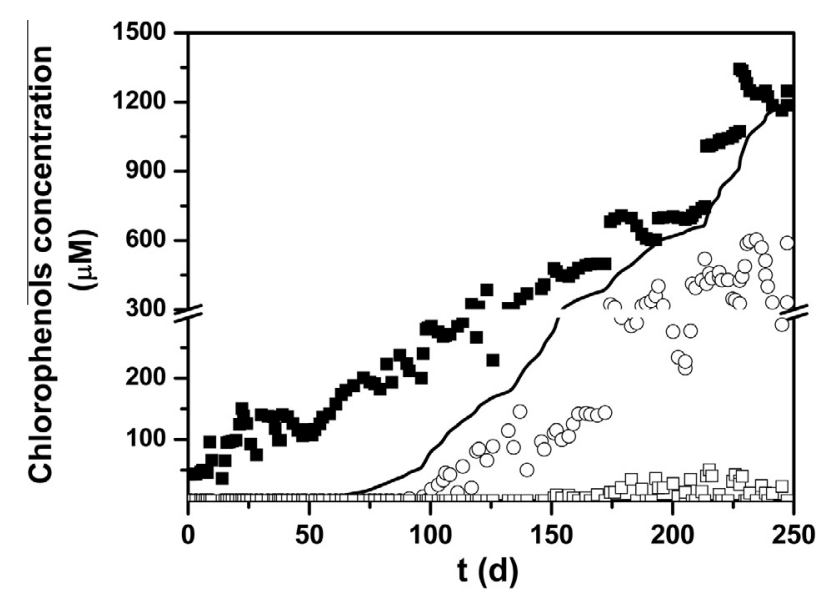

Fig. 3. Time course of inlet ( $\square)$ and exit $(\square)$ 246TCP concentrations, and the total chlorophenols concentration $(O)$ in the FBBR. The line depicts the predicted exit concentration of 246TCP by considering only adsorption onto GAC (Eq. (3)).

exit concentration of $246 \mathrm{TCP}$ continues being almost negligible up to the end of the 248 days of the experiment (see $X_{\text {TCP }}$ values of Table 2). Thus, dechlorination is associated to biological activity and this is clearly more efficient in the FBBR than in the EGSB system. Explanation of these differences requires a detailed analysis of the microbial population contained in the biofilm attached to the GAC.

The biofilm was gradually developed upon the operation time acquiring a stable and mature form, as was evidenced by SEM images (see Supplementary Material, Fig. S3). Bacteria were preferably attached to carbon fissures at early stages, but finally they were able to cover the entire carbon surface. Colonization of Desulfitobacterium species started during the bioaugmentation stage, reaching relative abundances of $28 \%$ and $16 \%$ of the biomass for $D$. hafniense and D. chlororespirans, respectively. Then, the presence of Desulfitobacterium decreased and the anaerobic community was gradually established and diversified, which gave rise to increasing COD reduction efficiencies. However, the increasingly high 246TCP-LR towards the end of the experiment favoured the selection of highly-resistant species with an increasing relative abundance of the halorespiring-bacteria, mainly of $D$. chlororespirans, which finally achieved $16 \%$ of the total biomass. This species was more abundant in the biofilms from the FBBR than in the granules of the EGSB-B at the end of the experiments, reinforcing the idea of its important role in the higher dechlorination efficiency of the former system.

The dechlorination efficiency of both EGSB-B and FBBR reactors seems to be quite high if comparing with values reported in the literature. Maximum volumetric dechlorination rates of 2.59 and $2.75 \mathrm{mmol} \mathrm{Cl}^{-}$removed $\mathrm{L}^{-1} \mathrm{~d}^{-1}$ have been achieved in the current work in EGSB-B and FBBR reactors, respectively. Other recent works reported values between 0.64 and $2 \mathrm{mmol} \mathrm{Cl}^{-}$removed $\mathrm{L}^{-1} \mathrm{~d}^{-1}$ treating 246TCP and 24DCP with different anaerobic and partially-aerobic reactors [10,28-30]. The results taken as a whole indicated that the bioaugmentation with Desulfitobacterium spp., in the case of the EGSB-B and FBBR, and the use of GAC as an adsorbent support, in the later, increased considerably the reactor efficiency and therefore appear as promising and robust alternatives for the abatement of the toxicity associated to chlorinecontaining species like chlorophenols.

A comparison between the stability of the EGSB and FBBR reactors was conducted by applying step and delta increases of 246TCP-LR. The step increase of the 246TCP-LR up to $5000 \mu \mathrm{mol} \mathrm{L}^{-1} \mathrm{~d}^{-1}$ increased the exit $246 \mathrm{TCP}$ concentration up to 2500, 2000 and $1000 \mu \mathrm{M}$ in the EGSB-NB, EGSB-B and FBBR, respectively, as can be seen in Fig. 4. The performance of the FBBR was recovered in $8 \mathrm{~h}$, whereas $24 \mathrm{~h}$ were needed for the EGSB 

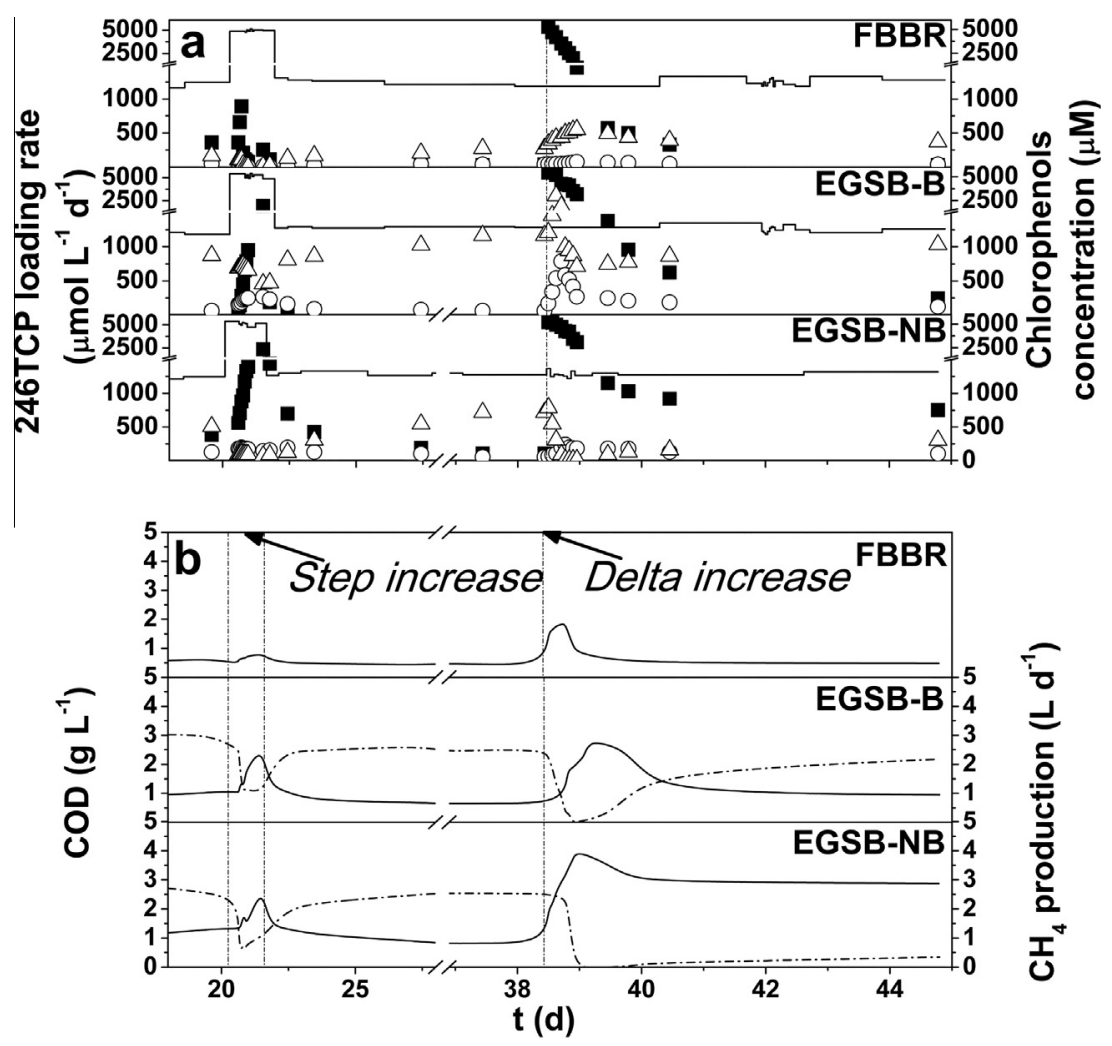

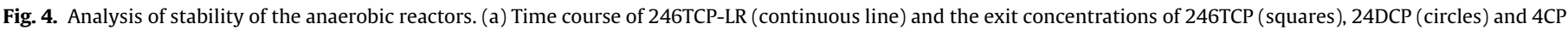
(triangles); (b) outlet COD values (continuous line) and methane production (dash line).

reactors. The increase of the $246 \mathrm{TCP}$ inlet concentration caused a competitive inhibition of 24DCP dechlorination, which explains the decrease of the $4 \mathrm{CP}$ concentration in the effluents. The exit COD increased above $2 \mathrm{~g} \mathrm{~L}^{-1}$ and the $\mathrm{CH}_{4}$ production lowered below $1 \mathrm{~L} \mathrm{~d}^{-1}$ in both EGSB reactors, whereas the performance of the FBBR was not significantly altered as depicted in Fig. 4.

The delta increase of inlet $246 \mathrm{TCP}$ concentration caused more remarkable differences in the stability of the reactors. The $\mathrm{CH}_{4}$ production was completely inhibited in the EGSB reactors and the exit COD increased up to values close to 4,3 and $1.9 \mathrm{~g} \mathrm{~L}^{-1}$ in the EGSBNB, EGSB-B and FBBR, respectively. After $6 \mathrm{~d}$ of the delta increase, the COD removal efficiencies were partially recovered reaching values of $23 \%, 75 \%$ and $87 \%$ in the EGSB-NB, EGSB-B and FBBR reactors, respectively. Exit 246TCP concentrations of 760, 240 and $25 \mu \mathrm{M}$ were respectively measured.

The presence of $D$. chlororespirans must play a relevant role in improving the response of the reactors to toxic shocks. The EGSB-B reactor and the FBBR, which contain a stable population of this species, showed a better performance than the EGSB-NB reactor. This species has been characterized as a versatile bacterium in the use of both electron donors and acceptors for the reductive dechlorination process compared with its counterparts of the genus Desulfitobacterium [31]. It has also shown a slightly higher biomass yield and specific activity than its congeners [19,32] (see also Supplementary Material, Fig. S1).

The GAC in the FBBR could alleviate significantly the effect of the sudden increase of 246TCP by protecting the activity of the biofilm, thus maintaining the COD in the discharge below $2 \mathrm{~g} \mathrm{~L}^{-1}$ and allowing high dechlorination efficiency. Adsorption of chlorophenols in aqueous phase occurs into micro and mesopores of activated carbon [33], which cannot be occupied by bacteria because of size exclusion. Dechlorinating bacteria attached into the GAC can remove $\mathrm{CP}$ present in the liquid media or adsorbed on the carbon surface, thus regenerating the adsorbent [34]. The combined action of biological reductive dechlorination and adsorption mitigates the toxic effect of CPs towards other microorganisms.

\subsection{Aerobic biodegradability and ecotoxicity}

Respirometric tests were carried out with the effluents from the EGSB-B reactor and FBBR in order to identify the best anaerobic system to be coupled with an aerobic step for the abatement of 246TCP and its degradation by-products. Table 3 summarizes the composition of the final effluents from the EGSB-B and FBBR experiments and the conversion values obtained in the subsequent aerobic biodegradability tests. Short chain organic acids were almost completely removed and $4 \mathrm{CP}$ was degraded by around $25 \%$, leading to about $60 \%$ COD reduction. Aerobic degradation of $246 \mathrm{TCP}$ and 24DCP was negligible. Fig. 5 shows the respirometric profiles obtained in the biodegradability tests. The SOUR values observed for the FBBR effluents were initially much higher than those of the EGSB-B reactor, consistently with the higher concentrations of chlorinated species in the second case.

Table 3

Exit concentrations from EGSB-B and FBBR and conversion values achieved in the aerobic biodegradability tests after $24 \mathrm{~h}$.

\begin{tabular}{lclcl}
\hline & $\begin{array}{l}\text { EGSB-B exit } \\
(\mu \mathrm{M})\end{array}$ & $\begin{array}{l}\text { Aerobic } \\
\text { conversion }(\%)\end{array}$ & $\begin{array}{l}\text { FBBR exit } \\
(\mu \mathrm{M})\end{array}$ & $\begin{array}{l}\text { Aerobic } \\
\text { conversion }(\%)\end{array}$ \\
\hline COD $\left(\mathrm{mg} \mathrm{L}^{-1}\right)$ & 1269 & 60 & 571 & 63 \\
246TCP & 73 & 0 & 21 & 0 \\
24DCP & 86 & 0 & 49 & 0 \\
4CP & 872 & 25 & 398 & 26 \\
Acetate & 9503 & $>99$ & 4476 & $>99$ \\
Propionate & 836 & $>99$ & 394 & $>99$ \\
\hline
\end{tabular}




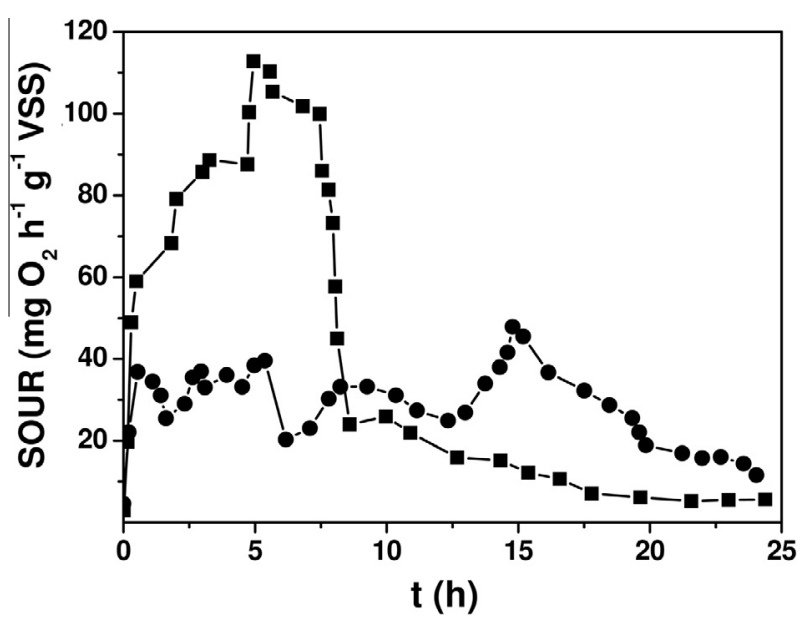

Fig. 5. SOUR profiles obtained for the effluents from the EGSB-B reactor (circles) and the FBBR (squares).

The Microtox ${ }^{\circledR}$ test yielded an increase of the ecotoxicity upon the anaerobic treatment experiment of Table 1 in the EGSB-B reactor (from the 23.4 T.U. initial value to 59.1 T.U. of the effluent). On the opposite, no change was observed in the case of FBBR $(24.4$ T.U. in the effluent). The ecotoxicity of both effluents was reduced by a $23 \%$ upon the aerobic biodegradability tests, which could be associated to the degradation of $4 \mathrm{CP}$ under aerobic conditions.

\subsection{Aerobic sequencing batch reactor experiments}

The aerobic respirometric test showed around 25\% conversion of 4CP (see Table 3). Thus, an aqueous solution containing a 4CP concentration similar to the maximum discharge concentration detected in the resulting effluents from the anaerobic reactors $(930 \mu \mathrm{M})$ was fed to the SBR. SBR was supplemented with nutrients (COD: $\mathrm{N}: \mathrm{P}=100: 0.5: 0.1$ ) and operated at different HRT for the sake of learning on the potential coupling of anaerobic and aerobic treatment. The ability of the mixed bacterial cultures for using chlorophenols as carbon and energy sources is associated to the selection and enrichment in SBR of specialized populations present in the consortium [13]. As can be seen in Fig. 6a, 4CP was completely converted in the SBR within a wide range of HRT (16-80 h). The rate of disappearance increased with the HRT due to the decrease of the maximum $4 \mathrm{CP}$ concentration inside the reactor after the filling stage. The highest specific degradation rate

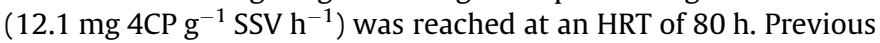
works have reported that the addition of cosubstrates and the use of operation strategies based on time control can increase the spe-

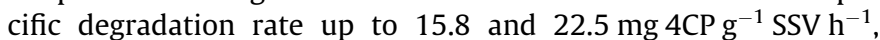
respectively $[13,14]$. At $10 \mathrm{~h}$ HRT a concentration of $750 \mu \mathrm{M}$ of 4CP was reached after filling, which caused the destabilization of the system (data not shown). A fraction of TOC showed to be refractory, representing about 35\% at the lowest HRT tested. This residual matter can be partially associated to microbial or excreted products from 4CP degradation [35], whose accumulation decreases as the discharge volume from the SBR in every cycle increases. The remaining TOC can be related to the presence of refractory microbial products, whose concentration is significantly reduced at decreasing HRT due to the lower decay rate.

Recent studies have concluded that the filling stage exerts a great influence on the removal efficiency of toxic compounds, so that a high long-term stability can be achieved by controlling that stage [36]. However, the effect of the inlet flow rate (IFR) used for filling has not been studied so far. Thus, the SBR was operated at different IFR and volume exchange ratios (VER). The time course
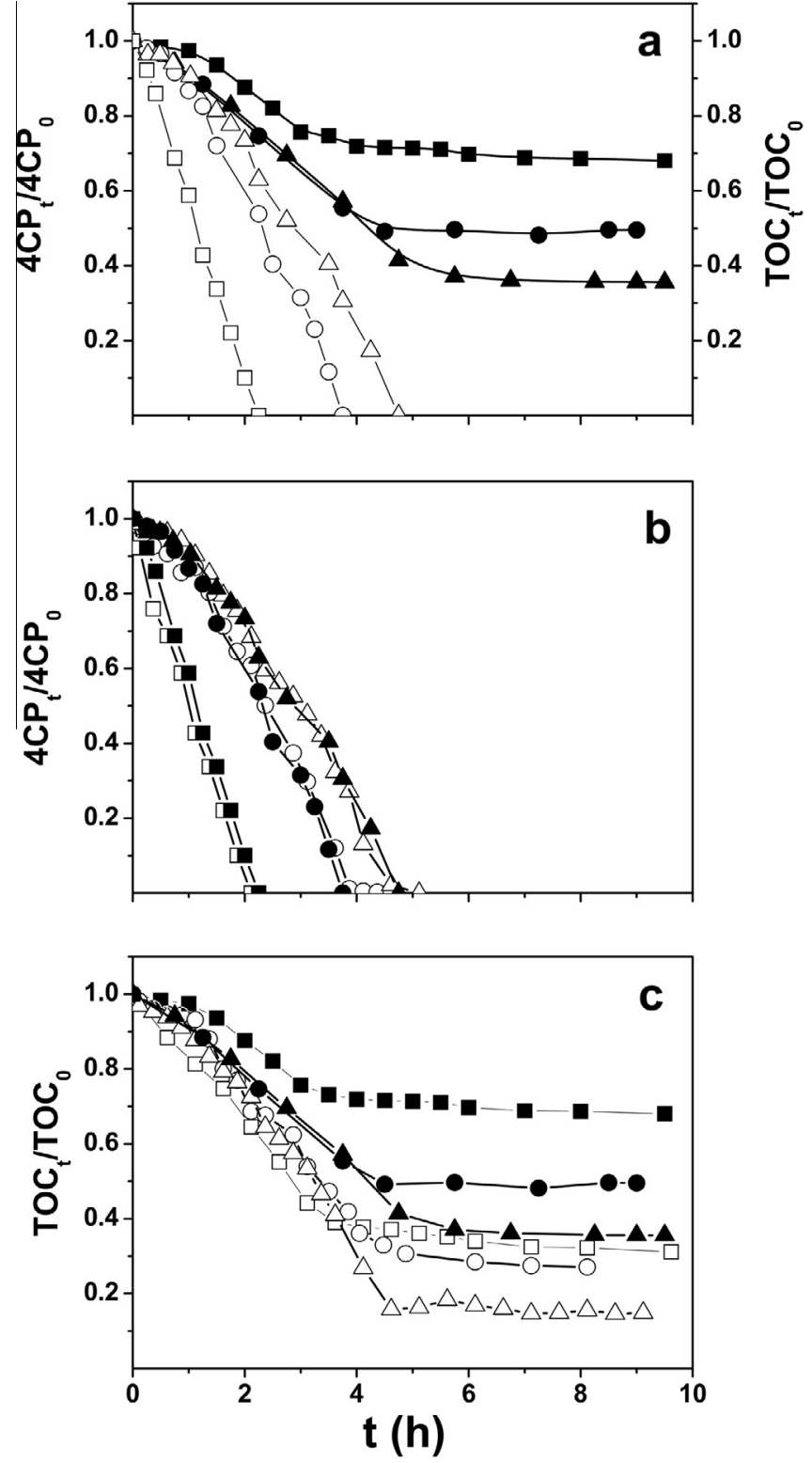

Fig. 6. Aerobic SBR performance. Time-evolution of $4 C P$ (open symbols) and TOC (solid symbols) in the SBR operated at HRT of 80 (squares), 23 (circles) and 16 (triangles) h (a); and time-evolution of 4CP (b) and TOC (c) at VER values of 0.10 (squares), 0.35 (circles) and 0.50 (triangles) in the SBR operated at IFR $=0.10$ (solid symbols) and $0.75 \mathrm{~L} \mathrm{~h}^{-1}$ (open symbols).

of normalized 4CP and TOC during the aerobic stage is depicted in Fig. $6 \mathrm{~b}$ and c. During these experiments the filling time was maintained constant at $30 \mathrm{~min}$, since a too short filling time would reduce the removal rates finally causing a complete destabilization of the system [37]. A maximum VER of 0.5 could be applied, indicating that concentrations of $4 \mathrm{CP}$ above $470 \mu \mathrm{M}$ at the end of the filling stage should be avoided since would lead to accumulation of 4CP destabilizing the SBR.

Decreasing the VER from 0.50 to 0.10 led to a reduction of the time required for complete conversion of $4 \mathrm{CP}$ from 4.75 to $2.25 \mathrm{~h}$ (Fig. 6b), since the maximum 4CP concentrations reached were 470 and $80 \mu \mathrm{M}$, respectively. Working at different IFR did not cause significant differences on the rate of disappearance of 4CP at any of the VER tested (Fig. 6b). However, the TOC removal rate was fairly improved when the IFR was increased from 0.10 to $0.75 \mathrm{~L} \mathrm{~h}^{-1}$ at given VER (Fig. 6c). Although increasing the 4CP concentration 
diminished the efficiency of the system, in this case, the increase of the VER from 0.1 to 0.5 at a given IFR reduced the TOC of the effluents from 50 to $7 \mathrm{mg} \mathrm{L}^{-1}$. 4-Chlorocathecol was identified as the main intermediate of aerobic 4-CP biodegradation, which was completely removed along the cycle. The ecotoxicity of the effluents resulting at 0.5 VER and $0.75 \mathrm{~L} \mathrm{~h}^{-1}$ IFR was around 4.5 $\mathrm{TU}$, thus allowing concluding that a significant reduction of the ecotoxicity of the effluents from the FBBR can be achieved by further treatment in SBR.

\section{Conclusions}

The dechlorination capacity of EGSB reactors adapted to 246TCP can be enhanced by bioaugmentation with Desulfitobacterium. Particularly, $D$. chlororespirans plays a key role in the improvement of the stability towards toxic shocks. The use of GAC as an adsorptive biofilm carrier in FBBR serves as a protective barrier against the 246TCP toxicity. The protection improves the reactor stability and dechlorination efficiency compared with EGSB reactors working at similar operating conditions. The high ecotoxicity of $4 \mathrm{CP}$ resulted from the 0 -dechlorination of 246TCP is significantly reduced using an aerobic SBR, where the abatement of chlorophenols is achieved by VER and IFR optimization.

\section{Acknowledgment}

The authors greatly appreciate financial support from the Spanish MCI through the project CTM2013-43803-P.

\section{Appendix A. Supplementary data}

Supplementary data associated with this article can be found, in the online version, at http://dx.doi.org/10.1016/j.cej.2014.07.134.

\section{References}

[1] D.V. Savant, R. Abdul-Rahman, D.R. Ranade, Anaerobic degradation of adsorbable organic halides (AOX) from pulp and paper industry wastewater, Bioresour. Technol. 97 (2006) 1092-1104.

[2] C. Meinert, E. Schymanski, E. Kuster, R. Kuhne, G. Schuurmann, W. Brack, Application of preparative capillary gas chromatography (pcGC), automated structure generation and mutagenicity prediction to improve effect-directed analysis of genotoxicants in a contaminated groundwater, Environ. Sci. Pollut. Res. Int. 17 (2010) 885-897.

[3] P. Chatonnet, A. Fleury, S. Boutou, Identification of a new source of contamination of Quercus sp. oak wood by 2,4,6-trichloroanisole and its impact on the contamination of barrel-aged wines, J. Agric. Food Chem. 58 (2010) 10528-10538.

[4] Q. Zhang, W. Yu, R. Zhang, Q. Zhou, R. Gao, W. Wang, Quantum chemical and kinetic study on dioxin formation from the 2,4,6-TCP and 2,4-DCP precursors, Environ. Sci. Technol. 44 (2010) 3395-3403.

[5] Y. Chen, J.J. Cheng, K.S. Creamer, Inhibition of anaerobic digestion process: a review, Bioresour. Technol. 99 (2008) 4044-4064.

[6] V. Saravanan, T.R. Sreekrishnan, Modelling anaerobic biofilm reactors - a review, J. Environ. Manag. 81 (2006) 1-18.

[7] J. Field, R. Sierra-Alvarez, Microbial degradation of chlorinated phenols, Rev. Environ. Sci. Biotechnol. 7 (2008) 211-241.

[8] M. Farhadian, D. Duchez, C. Vachelard, C. Larroche, Monoaromatics removal from polluted water through bioreactors-a review, Water Res. 42 (2008) 1325-1341.

[9] N. Yoshida, Y. Yoshida, Y. Handa, H.-K. Kim, S. Ichihara, A. Katayama, Polyphasic characterization of a PCP-to-phenol dechlorinating microbial community enriched from paddy soil, Sci. Total Environ. 381 (2007) 233-242.

[10] D. Puyol, A.F. Mohedano, J.L. Sanz, J.J. Rodríguez, Comparison of UASB and EGSB performance on the anaerobic biodegradation of 2,4-dichlorophenol, Chemosphere 76 (2009) 1192-1198.

[11] H. Yang, Z. Jiang, S. Shi, Aromatic compounds biodegradation under anaerobic conditions and their QSBR models, Sci. Total Environ. 358 (2006) 265-276.
[12] S. Semrany, L. Favier, H. Djelal, S. Taha, A. Amrane, Bioaugmentation: possible solution in the treatment of bio-refractory organic compounds (Bio-ROCs), Biochem. Eng. J. 69 (2012) 75-86.

[13] V.M. Monsalvo, A.F. Mohedano, J.A. Casas, J.J. Rodríguez, Cometabolic biodegradation of 4-chlorophenol by sequencing batch reactors at different temperatures, Bioresour. Technol. 100 (2009) 4572-4578.

[14] G. Buitrón, M.-E. Schoeb, I. Moreno-Andrade, J.A. Moreno, Evaluation of two control strategies for a sequencing batch reactor degrading high concentration peaks of 4-chlorophenol, Water Res. 39 (2005) 1015-1024.

[15] A. Vargas, I. Moreno-Andrade, G. Buitron, Controlled backwashing in a membrane sequencing batch reactor used for toxic wastewater treatment, J. Membr. Sci. 320 (2008) 185-190.

[16] G. Buitrón, I. Moreno-Andrade, V.M. Arellano-Badillo, V. Ramírez-Amaya, Membrane biofouling mechanism in an aerobic granular reactor degrading 4chlorophenol, Water Sci. Technol. 69 (2014) 1759-1767.

[17] Y.J. Chan, M.F. Chong, C.L. Law, D.G. Hassell, A review on anaerobic-aerobic treatment of industrial and municipal wastewater, Chem. Eng. J. 155 (2009) 118.

[18] D. Puyol, A.F. Mohedano, J.J. Rodriguez, J.L. Sanz, Effect of 2,4,6-trichlorophenol on the microbial activity of adapted anaerobic granular sludge biaugmented with Desulfitobacterium strains, New Biotechnol. 29 (2011) 79-89.

[19] R. Villemur, M. Lanthier, R. Beaudet, F. Lepine, The Desulfitobacterium genus, FEMS Microbiol. Rev. 30 (2006) 706-733.

[20] A. Polo, M. Tobajas, S. Sanchis, A.F. Mohedano, J.J. Rodríguez, Comparison of experimental methods for determination of toxicity and biodegradability of xenobiotic compounds, Biodegradation 22 (2011) 751-761.

[21] APHA, Standard methods for the examination of water and wastewater, in: A.D. Eaton, L.S. Clesceri, E.W. Rice, A.E. Greenberg (Eds.), 21st ed., American Public Health Association, Washington D.C., USA, 2005.

[22] P.A. Alphenaar, N. Groeneveld, A.C. Van Aelst, Scanning electron microscopical method for internal structure analysis of anaerobic granular sludge, Micron 25 (1994) 129-133.

[23] R.I. Amann, B.J. Binder, RJ. Olson, S.W. Chisholm, R. Devereux, D.A. Stahl, Combination of 16S rRNA-targeted oligonucleotide probes with flow cytometry for analyzing mixed microbial populations, Appl. Environ. Microbiol. 56 (1990) 1919-1925.

[24] M. Lanthier, B. Tartakovsky, R. Villemur, G. DeLuca, S.R. Guiot, Microstructure of anaerobic granules bioaugmented with Desulfitobacterium frappieri PCP-1, Appl. Environ. Microbiol. 68 (2002) 4035-4043.

[25] E. Stackebrandt, Nucleic Acid Techniques in Bacterial Systematics, Wiley, 1991.

[26] G. Collins, C. Foy, S. McHugh, V. O'Flaherty, Anaerobic treatment of 2,4,6trichlorophenol in an expanded granular sludge bed-anaerobic filter (EGSBAF) bioreactor at $15{ }^{\circ} \mathrm{C}$, FEMS Microbiol. Ecol. 53 (2005) 167-178.

[27] B.H. Hameed, I.A.W. Tan, A.L. Ahmad, Preparation of oil palm empty fruit bunch-based activated carbon for removal of 2,4,6-trichlorophenol: optimization using response surface methodology, J. Hazard. Mater. 164 (2009) 1316-1324.

[28] C. Garibay-Orijel, E. Ríos-Leal, J. García-Mena, H.M. Poggi-Varaldo, 2,4,6Trichlorophenol and phenol removal in methanogenic and partially-aerated methanogenic conditions in a fluidized bed bioreactor, J. Chem. Technol. Biotechnol. 80 (2005) 1180-1187.

[29] A.G.-D. Jesús, F.J. Romano-Baez, L. Leyva-Amezcua, C. Juárez-Ramírez, N. RuizOrdaz, J. Galíndez-Mayer, Biodegradation of 2,4,6-trichlorophenol in a packedbed biofilm reactor equipped with an internal net draft tube riser for aeration and liquid circulation, J. Hazard. Mater. 161 (2009) 1140-1149.

[30] H.M. Poggi-Varaldo, J.D. Bárcenas-Torres, C.U. Moreno-Medina, J. García-Mena, C. Garibay-Orijel, E. Ríos-Leal, N. Rinderknecht-Seijas, Influence of discontinuing feeding degradable cosubstrate on the performance of a fluidized bed bioreactor treating a mixture of trichlorophenol and phenol, J. Environ. Manage. 113 (2012) 527-537.

[31] A.M. Cupples, R.A. Sanford, G.K. Sims, Dehalogenation of the herbicides bromoxynil (3,5-dibromo-4-hydroxybenzonitrile) and ioxynil (3,5-diiodino-4hydroxybenzonitrile) by Desulfitobacterium chlororespirans, Appl. Environ. Microbiol. 71 (2005) 3741-3746.

[32] R. Villemur, The pentachlorophenol-dehalogenating Desulfitobacterium hafniense strain PCP-1, Philos. Trans. R. Soc. B 368 (2013).

[33] L. Li, P.A. Quinlivan, D.R.U. Knappe, Effects of activated carbon surface chemistry and pore structure on the adsorption of organic contaminants from aqueous solution, Carbon 40 (2002) 2085-2100.

[34] M.F. Carvalho, A.F. Duque, I.C. Gonçalves, P.M.L. Castro, Adsorption of fluorobenzene onto granular activated carbon: isotherm and bioavailability studies, Bioresour. Technol. 98 (2007) 3424-3430.

[35] M.H. Kim, O.J. Hao, Cometabolic degradation of chlorophenols by Acinetobacter species, Water Res. 33 (1999) 562-574.

[36] M.J. Betancur, J.A. Moreno, I. Moreno-Andrade, G. Buitrón, Practical optimal control of fed-batch bioreactors for the waste water treatment, Int. J. Robust Nonlinear Control 16 (2006) 173-190.

[37] E. Sahinkaya, F.B. Dilek, Effect of feeding time on the performance of a sequencing batch reactor treating a mixture of 4-CP and 2,4-DCP, J. Environ. Manag. 83 (2007) 427-436. 